\title{
Sistema agroindustrial do leite no Maranhão: uma análise prototípica
}

\author{
Agroindustrial system of milk in Maranhão: a prototypical analysis \\ Eliene Cristina Barros Ribeiro' (1), Cleber Augusto Pereira' (1), Maria Daniela Alves Bezerra1 (1), \\ Natália Ingrid Silvino Sampaio ${ }^{10}$, Pablo Francisco Sousa Carvalho' \\ 1Departamento de Ciências Contábeis, Universidade Federal do Maranhão (UFMA), Imperatriz (MA), Brasil. E-mails: elienecbr@ \\ hotmail.com; cleber.pereira@ufma.br; mariadaniela_09@gmail.com; nataliasampaio80@gmail.com; pablofsc97@gmail.com
}

\begin{abstract}
Como citar: Ribeiro, E. C. B., Pereira, C. A., Bezerra, M. D. A., Sampaio, N. I. S., \& Carvalho, P. F. S. (2022). Sistema agroindustrial do leite no Maranhão: uma análise prototípica. Revista de Economia e Sociologia Rural, 60(4), e240762.
\end{abstract} https://doi.org/10.1590/1806-9479.2021.240762

Resumo: Objetivou-se identificar a forma como os agentes do sistema agroindustrial do leite no sul e oeste do Maranhão percebem e praticam a produção e a comercialização do leite, bem como as relações entre estes, buscando articular estratégias competitivas regionais. Trata-se de uma pesquisa multicasos qualitativa, com dados coletados mediante entrevistas semiestruturadas, com a utilização da técnica de associação livre de palavras (TALP). Para a avaliação dos resultados, optou-se pelo uso da análise de frequências múltiplas, análise de similitude e elaboração de matriz prototípica. Participaram das entrevistas 23 agentes divididos em quatro grupos, sendo os gestores institucionais responsáveis em apoiar a cadeia do leite, pequenos produtores de leite e laticínios. Nos resultados, foi possível identificar um padrão de opiniões sobre os desafios da produção, bem como aspectos de comercialização do leite considerados importantes institucional e organizacionalmente. Percebeu-se que a infraestrutura e a logística de transporte se posicionaram como sérios obstáculos ao crescimento do mercado leiteiro na região. Além disso, o estudo demonstrou que há uniformidade de critérios considerados importantes para o mercado, como qualidade do leite, higiene na produção, sanidade animal, uso de ordenha mecânica e cumprimento pelos produtores quanto à assistência técnica.

Palavras-chave: sistema agroindustrial do leite, análise prototípica, produção, comercialização.

\begin{abstract}
This research aimed to identify how agents of the Agro-industrial System of milk in the South and West of Maranhão perceive and practice milk production and commercialization, and the relations among them, seeking to articulate regional competitive strategies. It is a qualitative multi-case study with a semi-structured interview script guided by the Free Word Association Technique (TALP) for data collection. We have used Multiple Frequency Analysis, Similitude Analysis, and a Prototypical matrix formulation to evaluate the results. Twenty-nine agents have participated in the interviews. They were divided into four groups, composed of institutional managers responsible for supporting the milk chain, small producers of milk and dairy products, and dairy products companies' managers. The results enable to identify a pattern of opinions about production challenges and milk commercialization essential aspects, both institutionally and organizationally. Infrastructure and transport logistics were pointed out as severe obstacles to the dairy market growth in the region. Moreover, the study has evidenced the existence of a uniform position on important criteria for the market, such as milk quality, production hygiene, animal health, mechanical milking usage, and compliance with technical assistance by producers.
\end{abstract}

Keywords: agroindustrial system of milk, prototypical analysis, production, commercialization.

\section{INTRODUÇÃO}

A pecuária leiteira é uma das principais atividades do agronegócio brasileiro, desempenhando vital relevância no processo de desenvolvimento econômico e social do país, principalmente na renda do pequeno produtor. O setor produtivo conta com 1,3 milhão de propriedades leiteiras situadas em 99\% do território brasileiro, algumas mais tecnificadas do que outras e cerca de 4 milhões de trabalhadores (Instituto Brasileiro de Geografia e Estatística, 2018a; Empresa 
Brasileira de Pesquisa Agropecuária, 2019). A produção leiteira movimenta a economia de pequenos municípios, gerando distribuição de renda e empregos permanentes, principalmente na esfera rural. O setor cria oportunidades, mas também se reveste de desafios, que passam pela necessidade de formação e qualificação dos pequenos produtores, adequação dos serviços de assistência técnica, melhora da qualidade do leite, aumento da eficiência dos sistemas de comercialização e dos fatores de produção. A combinação desses elementos é essencial para garantir o crescimento da produção, produtividade e competitividade do leite nos mercados nacional e internacional (Rauta et al., 2017). Segundo o MAPA (Brasil, 2012) e o Ministério da Mulher, Família e Direitos Humanos (Brasil, 2020), pequeno produtor é aquele que possui receita bruta anual de até $\mathrm{R} \$ 160.000,00$ ou até quatro módulos fiscais de terra.

A produção brasileira de leite em 2018 foi de 33,8 bilhões de litros, com projeção de crescimento de 2,5\% em 2019, tendo colocado o Brasil em sexto lugar no ranking mundial dos países produtores (Empresa Brasileira de Pesquisa Agropecuária, 2020). Para atender ao crescimento da população e, consequentemente, do consumo de lácteos, o volume produzido no Brasil, em 2026, deverá atingir o patamar de 48 bilhões de litros. É notório o destaque dessa atividade, considerando a não necessidade de extensas faixas de terra, no caso dos pequenos produtores, bem como o fato de ser empregadora de grande contingente de mão de obra, com significativa participação na formação da renda regional (Palencia, 2016; Balde Branco, 2016).

Pode-se dizer que o sistema agroindustrial (SAG) do leite no Brasil passou por mudanças estruturais desde o final da década de 1980, culminando em mudanças nos ambientes institucionais e competitivos. Quanto às mudanças institucionais, destaca-se a Instrução Normativa (IN) n 51/2002 (atualmente IN, n 62/2011) que passou a fixar os requisitos mínimos de qualidade sobre o leite cru nas propriedades ruais. O leite passa a ser refrigerado na propriedade, o que ainda tem causado forte impacto aos pequenos produtores, em razão da pequena escala de produção, além de impor condições prévias de infraestrutura de refrigeração nas propriedades. Esses fatores passaram a exigir mais organização nos processos estruturais, de comercialização, nos contratos e organizações associativas e cooperativas (Campos et al., 2016; Golban \& Golban, 2017).

Portanto, uma gestão eficiente da qualidade do leite é fundamental, mediante as normas institucionais, tornando a propriedade mais eficiente na gestão dos recursos e elevando a produtividade. Produzir leite de qualidade envolve o gerenciamento da fazenda, que inclui investir na gestão da alimentação animal, higiene das instalações e operações de ordenha, nas condições de armazenamento do leite, entre outros fatores. Programas de pagamento baseados na qualidade do leite são utilizados em vários países do mundo, inclusive no Brasil, como incentivo para melhorar os processos de produção, ou seja, laticínios oferecem recompensas financeiras aos produtores que atendem aos parâmetros de qualidade estipulados institucionalmente (Busanello et al., 2017; Gonçalves et al., 2017).

A pecuária leiteira apresenta duas características relevantes: ocorre em todo o território nacional e a inexistência de grande padrão de produção. No Brasil, há propriedades de subsistência sem nenhuma técnica de produção, que produzem, diariamente, 80 litros/leite/dia, em contraste com produtores com sistemas de produção que chegam a 16.238 litros/leite/dia, podendo ser competitivos em âmbito internacional (Sorio, 2018; Telles et al., 2017). Na região Nordeste, a produção de leite equivale a $13,0 \%$ da produção nacional, apresentando aproximadamente 4,3 bilhões de litros. Nesse contexto, o estado do Maranhão está em quinto lugar no ranking dos estados nordestinos e em $17^{\circ}$ no ranking nacional, apresentando produção de pouco mais de 345 milhões de litros em 2018 (Instituto Brasileiro de Geografia e Estatística, 2018b). Entre as mesorregiões do Maranhão, o sul e o oeste apresentam, respectivamente, 59\% e $20 \%$ da 
produção no estado, o que justifica a delimitação geográfica proposta neste projeto. Porém, a intensificação do uso da terra com tecnologia apropriada ainda é incipiente quando se trata da atividade leiteira proveniente de pequenos produtores (Oliveira, 2016).

Destarte, este trabalho objetiva identificar a forma como os agentes do SAG do leite no sul e oeste do Maranhão percebem e praticam a produção e a comercialização do leite, bem como as relações entre os agentes, buscando articular estratégias competitivas regionais. Aspectos referentes à competitividade do SAG do leite para essa proposta são mencionados na tentativa de caracterizar as dinâmicas social e estrutural que apresentam particularidades plurais e heterogêneas. Acredita-se que os dados dessa pesquisa serão úteis para estratégias de investimentos do setor produtivo do leite no estado, que tem apresentado potencial de crescimento e desenvolvimento regional.

Assim, esse trabalho se fundamenta nas lentes teóricas do ambiente institucional e do SAG do leite, mediante uma análise prototípica. Essa combinação de análises é inovadora no setor rural e pode trazer a realidade da produção e comercialização dos pequenos produtores no Maranhão. Destaca-se que a região sudoeste do Maranhão é reconhecida como a maior bacia leiteira do estado, porém marcada pela baixa tecnologia na produção e pela informalidade na comercialização do leite (Oliveira, 2016; Silva Filho \& Figueira, 2019). Assim, este trabalho trará resultados úteis a intervenções com base em políticas públicas quanto à produção rural e gestão dos relacionamentos no SAG do leite.

\section{O SAG DO LEITE E AS RELAÇÕES ENTRE OS AGENTES}

O SAG contempla a ideia de organização sistêmica que coordena parte das cadeias produtivas agroalimentares e compreende um conjunto de agentes econômicos, posicionados sequencialmente antes, dentro e depois da porteira. Esses agentes são responsáveis por diferentes etapas da produção, transformação e comercialização de um produto de origem do agronegócio até chegar ao consumidor final (Figura 1) (Zylbersztajn, 1995).

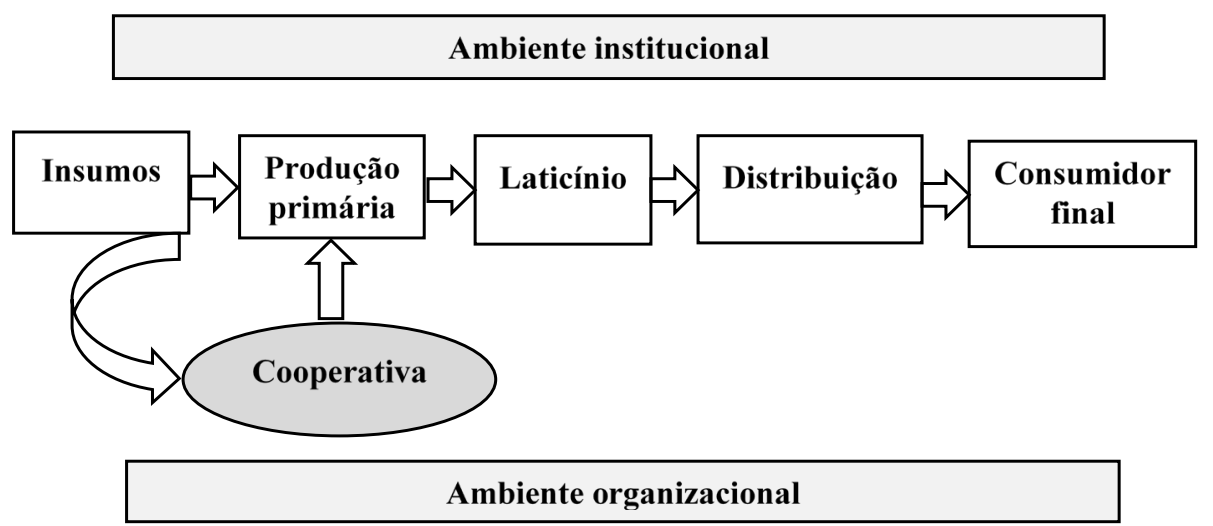

Figura 1. Representação do SAG. Fonte: adaptada de Zylbersztajn (1995).

O ambiente institucional é representado pelas instituições sociais, econômicas, governamentais, políticas, religiosas e científicas que criam normas e regras que devem ser cumpridas pelas organizações para se legitimarem no mercado. Dessa forma, o ambiente institucional é visto na perspectiva dos fatores que influenciam o formato, as práticas e o desempenho das organizações do SAG, envolvendo os interesses de diversos agentes. Já o ambiente organizacional configura o 
conjunto de organizações relacionadas entre si em uma mesma área institucional reconhecida, sendo representado pelos fornecedores, clientes, agências reguladoras do setor, competidores e stakeholders (Vega \& Keenan, 2016; Krell et al., 2016).

As propriedades rurais são marcadas por desafios e oportunidades que vão do campo das inovações, qualidade, agilidade, sustentabilidade, de maneira que, para além das trocas econômicas, há outros tipos de trocas relevantes, como trocas sociais, legais, tecnológicas, planejamentos, informações e conhecimentos (Börjeson, 2015). Assim, entre os diversos agentes do SAG do leite, destaca-se no elo "antes da porteira" os fornecedores de insumos, como máquinas e equipamentos, adubos, forragens, suplementos minerais, produtos veterinários, entre outros. Já no elo "dentro da porteira", tem-se a produção primária do leite, envolvendo produtores especializados que tem a atividade como a principal fonte de renda, investindo em tecnologia, rebanhos leiteiros especializados, economias de escala, entre outros (Meehan et al., 2016). Já os produtores não especializados evidenciam na atividade uma complementação de renda, com um rebanho misto, utilizado tanto para fins de produção leiteira como para gado de corte, representando uma atividade de subsistência (Palencia, 2016). No elo "depois da porteira", encontra-se a indústria de processamento, podendo ser nacional, multinacional, cooperativa e pequenos laticínios. O elo distribuição é composto do atacado e varejo, como supermercados, restaurantes, padarias, como também da venda direta ao consumidor final, de maneira formal ou informal.

Ressalta-se que a comercialização do leite via pequenos produtores está ligada a uma estrutura de mercado denominada oligopsônio, o que indica que, nesse processo, há grande quantidade de produtores com o intuito de vender seu produto e uma restrita proporção de compradores (Azevedo \& Politi, 2008; Scalco \& Braga, 2014). Estima-se que 2,3\% das propriedades leiteiras são especializadas e atuam como empresa rural eficiente. Entretanto, mais de $90 \%$ dos produtores são considerados pequenos ou familiares, com baixo volume de produção diária, baixa produtividade por animal e pouco uso de tecnologias. Assim, a formação de preço do leite in natura passa a ser predominantemente influenciada pela indústria de laticínios, uma vez que pequenos agricultores individuais não possuem poder de barganha nesse mercado (Palencia, 2016).

As indústrias de laticínios têm buscado com os produtores de leite um produto com qualidade e confiabilidade, havendo, assim, necessidade de mais comprometimento de toda a cadeia no aspecto higiênico e sanitário, com adequação e acompanhamento das práticas de manejo (Telles et al., 2017). Para competir no mercado, a pecuária leiteira regional precisa se adequar à utilização eficiente dos insumos, aperfeiçoamento da tecnologia e especialização da mão de obra. As recompensas financeiras são provenientes de regras institucionais mediante a qualidade do leite, no que tange à sanidade animal, à higiene na ordenha e a instalações de armazenagem do leite, entre outras (Botaro et al., 2013; Empresa Brasileira de Pesquisa Agropecuária, 2015).

Há três formas de pagamento pela qualidade do leite mais utilizadas atualmente, em âmbito regional, e que se adequam à realidade da região analisada neste artigo (Durr, 2012).

$\checkmark$ Remuneração por infraestrutura e limites mínimos de qualidades - as indústrias remuneram melhor produtores que adotam tecnologias apropriadas à qualidade do leite, sistema esse utilizado em bacias leiteiras pouco especializadas. A principal vantagem é que permite aos produtores atingirem rapidamente condições para serem premiados, estimulando investimentos.

$\checkmark$ Remuneração baseada no destino industrial do leite - o preço varia conforme o tipo de produto industrializado, sendo mais utilizado por empresas que trabalham com derivados 
lácteos específicos ou com poucos produtos. A principal vantagem é que o preço da matériaprima é vinculado diretamente ao preço do produto industrializado, sendo possível mais equidade nas margens de lucro de cada elo da cadeia.

$\checkmark$ Remuneração baseada nos componentes do leite - os produtores são remunerados pela quantidade de cada componente do leite que possua valor industrial (gordura, proteína, entre outros) e penalizam por problemas de integridade do leite. O sistema é utilizado em bacias leiteiras especializadas. A principal vantagem é o constante estímulo ao investimento na qualidade, que é avaliada pela indústria com base no produto comercializado

Essa condição, entretanto, parece satisfazer produtores e processadores, que se amparam no regramento formal e organismos privados para obter mais estabilidade nas transações (Acosta et al., 2018). Dessa forma, esse trabalho se apresenta como relevante, quando propõe analisar e conhecer o SAG do leite, envolvendo questões organizacionais, institucionais e o relacionamento entre os agentes, baseado na análise prototípica, com relevância aos aspectos regionais.

\section{METODOLOGIA}

Para o desenvolvimento deste trabalho, apresentou-se um estudo multicasos qualitativo, destacando-se como lente teórica o SAG do leite mediante a análise TALP, como um dos contributos deste trabalho. As regiões analisadas foram o sul e oeste do Maranhão, mais especificamente conhecidas como sub-regiões tocantina e pré-amazônica, consideradas a maior bacia leiteira do estado do Maranhão, como segue:

- Região sul do Maranhão - envolveu pequenos produtores de leite de seis municípios: Porto Franco, Estreito, Alegre do Maranhão, Nova Colinas, Sambaíba e Alto Parnaíba.

- Região oeste do Maranhão - envolveu pequenos produtores de leite de 23 municípios: Imperatriz, João Lisboa, Lajeado Novo, Montes Altos, Ribamar Fiquene, Amarante do Maranhão, Buritirana, São Francisco do Brejão, São Pedro da Água Branca, Vila Nova dos Martírios, Pindaré-Mirim, Santa Inês, Santa Luzia, Tufilândia, Bom Jardim, Alto Alegre do Pindaré, Senador La Rocke, Açailândia, Bom Jesus da Selva, Cidelândia, Itinga do Maranhão, Campestre e São João do Paraíso.

Os agentes entrevistados foram divididos em quatro grupos distintos: (i) produtores familiares de leite; (ii) gestores institucionais responsáveis em apoiar a cadeia do leite na região; (iii) gestores das associações e cooperativas; (iv) gestores dos laticínios. Participou do estudo um total de 23 agentes, sendo nove produtores de leite, nove representantes de laticínios, dois gestores institucionais responsáveis em apoiar a cadeia do leite, dois gestores de cooperativas e um gestor de associação. Os agentes entrevistados foram selecionados mediante o tempo na atividade (mais de dez anos na produção de leite), uma vez que possuem um vasto conhecimento do setor.

Entrevistas com roteiros semiestruturados foram realizadas entre dezembro de 2019 e maio de 2020, mediante a técnica TALP, foram gravadas e tiveram duração total de 30 a 40 minutos cada uma.

\subsection{Técnica de Análise Livre de Palavras (TALP) e os indutores adotados no estudo}

A TALP é uma técnica projetiva, baseada em estímulos, que, partindo de um objeto indutor, consegue captar e receber informações que poderiam estar ocultas ou não, e, por meio de uma resposta associativa a uma imagem ou a uma palavra, é possível revelar aspectos, opiniões, 
pensamentos e personalidades dos indivíduos (Tavares et al., 2014). O estímulo escolhido foi uma pergunta indutora, aplicada individualmente a cada grupo, respondida com as cinco primeiras palavras que viessem à mente do entrevistado. As perguntas foram previamente definidas em função do objeto representacional, levando em consideração também as características da amostra ou sujeitos da pesquisa dos entrevistados, conforme indica (Coutinho et al., 2003).

Para cada grupo entrevistado, foi elaborada uma pergunta como segue:

i) Produtores de leite: o que faz o seu leite ser melhor que o do concorrente?

ii) Laticínios: quais os cinco pontos essenciais para que o laticínio adquira leite de um pequeno produtor?

iii) Gestores institucionais responsáveis em apoiar a cadeia do leite, associações e cooperativas: quando se fala em cadeia do leite, quais as cinco primeiras palavras que vêm a sua mente? As respostas foram transcritas em planilhas eletrônicas do programa Exce/e depois tratadas no software Iramuteq. O Iramuteq permite que se trabalhe com matrizes que envolvam variáveis categoriais e listas de palavras, tais quais aquelas utilizadas para analisar tarefas de evocações livres. Nesse caso, o software auxiliou na contagem de frequência, na análise prototípica e na análise de similitude adotadas nesta pesquisa.

\subsubsection{Análises aplicadas às respostas}

A análise de frequências múltiplas permite, por meio de relatório, expor as principais palavras que se destacaram por ordem de frequência nas evocações. A análise de similitude apresenta a relação e o grau de conectividade entre os termos da estrutura da representação social e pode ser ilustrada por um grafo utilizando árvore máxima. Já a análise prototípica é uma das principais técnicas para analisar ou tratar as representações sociais e ocorre a partir de critérios de frequência e ordem de evocações, sendo representada por uma figura que possui quatro quadrantes: núcleo central, primeira periferia, segunda periferia e zona de contraste (Donato et al., 2017).

O núcleo central (superior esquerdo) é o quadrante mais importante. Essa zona aponta o centro das representações geradas e é formada por palavras com mais ocorrências e uma ordem média de evocações (OME) abaixo da média (Wachelke et al., 2016). A primeira periferia (superior direito) apresenta os termos que dão força e sustentam os conceitos encontrados no núcleo central. São elementos que possuem alta frequência e OME mediana. No terceiro quadrante (inferior esquerdo), localiza-se a segunda periferia. Neste, as palavras possuem baixa frequência e alta OME. Essa zona se refere a elementos com poucos destaques nas duas coordenadas, portanto menos interessantes para a estrutura da representação social, pois trazem aspectos mais particularizados (Santos et al., 2019).

A zona de contraste (inferior direito) são respostas minoritárias que podem indicar algumas possibilidades ou apenas complementos da primeira periferia; indica o início de uma representação social que virá no futuro ou a existência de um subgrupo que valoriza consistentemente alguns elementos distintos da maioria, talvez até mesmo com um núcleo central diferente. Cada quadrante é definido pela OME. A frequência da palavra refere-se a quantas vezes se repetiu na análise. Quanto mais a palavra se repetir nas primeiras evocações, maior será sua importância. A OME refere-se à distribuição das palavras. Quanto mais distante o termo evocado estiver da primeira palavra evocada, maior será a OME. Para chegar à OME, utiliza-se a Equação 1 (Correia \& Joia, 2014):

$\mathrm{OME}=\frac{(\mathrm{f} 1 * 1)+(\mathrm{f} 2 * 2)+(\mathrm{f} 3 * 3)+(\mathrm{f} 4 * 4)+(\mathrm{f} 5 * 5)}{\Sigma \mathrm{f}}$ 
Onde $f 1, f 2, f 3, f 4$ e $f 5$ representam a porção de vezes em que as palavras foram evocadas em primeiro, segundo, terceiro, quarto e quinto lugares e seus respectivos pesos aplicados a cada posição divididos pelo somatório de vezes em que o termo apareceu.

\subsubsection{Preparação e lematização das matrizes de resposta}

Após a coleta dos dados, foram feitas adaptações ao universo das respostas para garantir o conteúdo e a similaridade semântica dos termos evocados. Para isto, os termos foram reduzidos ao singular e à forma masculina. Também foi utilizado um dicionário de dados para garantir que os termos homônimos fossem reduzidos ao mesmo radical.

\subsection{Matriz de respostas por categoria de respondentes}

Para melhor compreensão das informações, as adequações foram divididas em subtítulos por grupos de agentes. Para cada grupo, foi elaborada uma tabela com as mudanças realizadas conforme descritas a seguir.

\subsubsection{Produtores de leite}

As adaptações efetuadas podem ser exemplificadas pelos ajustes: as palavras "baixo CSS'" e "baixo CBT2" foram substituídas por "higiene" e "sanidade animal", respectivamente. A palavra "alimentação" foi substituída onde não houvesse repetição por já ter sido evocada, pelo termo "dieta apropriada". Os termos "acidez", "sanidade" e "sadio" foram substituídos por "sanidade animal". "Melhor laticínio" por "laticínio". "Puro" por "leite sem resíduos". "Manejo" por "manejo do gado". As substituições foram feitas sem prejuízo ao significado de cada palavra, ou seja, mantendo o mesmo critério semântico. Os resultados já ajustados quanto aos produtores de leite seguem na matriz apresentada na Tabela 1.

Tabela 1. Respostas dos produtores de leite quanto ao termo indutor

\begin{tabular}{|c|c|c|c|c|c|}
\hline Produtores & Palavra 1 & Palavra 2 & Palavra 3 & Palavra 4 & Palavra 5 \\
\hline $\begin{array}{l}\text { São Franc. do } \\
\text { Brejão }\end{array}$ & Qualidade & Proteína & Higiene & Sanidade animal & Gordura \\
\hline Buritirana & Qualidade & Higiene & $\begin{array}{l}\text { Sanidade } \\
\text { animal }\end{array}$ & $\begin{array}{l}\text { Tanque de } \\
\text { resfriamento }\end{array}$ & Laticínio \\
\hline Buritirana & Leite & Fonte de renda & Preço & Vaca & Qualidade \\
\hline Campestre & Qualidade & Manejo do gado & $\begin{array}{l}\text { Sanidade } \\
\text { animal }\end{array}$ & Dieta apropriada & Alimentação \\
\hline $\begin{array}{l}\text { São João do } \\
\text { Paraíso }\end{array}$ & $\begin{array}{c}\text { Antibiótico } \\
\text { homeopático }\end{array}$ & Higiene & $\begin{array}{l}\text { Leite sem } \\
\text { resíduos }\end{array}$ & Coar leite & $\begin{array}{l}\text { Manejo do } \\
\text { gado }\end{array}$ \\
\hline $\begin{array}{l}\text { Buritirana } \\
\text { povoado } \\
\text { Tanque } 2\end{array}$ & Ordenha mecânica & Diferenciado & Gostoso & Sanidade animal & Higiene \\
\hline $\begin{array}{l}\text { Senador La } \\
\text { Roque }\end{array}$ & Ordenha mecânica & Higiene & $\begin{array}{l}\text { Leite sem } \\
\text { resíduos }\end{array}$ & Confiável & Qualidade \\
\hline Porto Franco & Dieta apropriada & Higiene & Laticínio & Qualidade & Quantidade \\
\hline Amarante & Qualidade & Sanidade animal & $\begin{array}{c}\text { Dieta } \\
\text { apropriada }\end{array}$ & Manejo do gado & Higiene \\
\hline
\end{tabular}

Fonte: elaboração própria.

1 O termo CSS significa higiene.

2 O termo CBT significa sanidade animal. 


\subsubsection{Gestores institucionais, associações e cooperativas}

Algumas adaptações foram feitas ao universo das respostas: as palavras "produtor", "potencialidade" e "produção" foram substituídas por "produtividade"; a palavra "indústria", por "agroindústria"; o termo "conhecimento tecnológico", por "conhecimento"; "logística", por "acesso adequado"; "preço do leite" por "preço". Os resultados constam na Tabela 2.

Tabela 2. Respostas dos gestores institucionais, associações e cooperativas ao termo indutor

\begin{tabular}{|c|c|c|c|c|c|}
\hline Agentes & Palavra 1 & Palavra 2 & Palavra 3 & Palavra 4 & Palavra 5 \\
\hline 1 Gestor Sebrae & União & Engrenagem & $\begin{array}{l}\text { Acesso } \\
\text { adequado }\end{array}$ & Produtividade & Conhecimento \\
\hline 2 Gestor Senar & Vaca & Agroindústria & Preço & Mercado & Produtividade \\
\hline $\begin{array}{l}3 \text { Cooperativa } 1 \\
\text { (Vila Nova) }\end{array}$ & Produtividade & $\begin{array}{l}\text { Assistência } \\
\text { técnica }\end{array}$ & Agroindústria & Consumidor & Capacitação \\
\hline $\begin{array}{l}4 \text { Cooperativa } 2 \\
\text { (Sítio Novo) }\end{array}$ & $\begin{array}{l}\text { Manejo do } \\
\text { gado }\end{array}$ & Qualidade & $\begin{array}{l}\text { Acesso } \\
\text { adequado }\end{array}$ & Preço & Capacitação \\
\hline $\begin{array}{l}5 \text { Associação (São } \\
\text { Miguel) }\end{array}$ & Incentivo & Conhecimento & Qualidade & Produtividade & Preço \\
\hline
\end{tabular}

Fonte: elaboração própria.

\subsubsection{Laticínios}

As seguintes adaptações foram realizadas: "volume" e "quantidade disponível" foram substituídos por "volume produzido". A palavra "rota especifica", por "logística". O termo "melhorar rebanho" foi substituído por "rebanho com melhorias genéticas", "quantidade de CBT", "saúde do animal" e "sanidade adequada" por "sanidade animal".

A palavra "células somáticas" e "higiene de produção" por "higiene". "Acesso" e "localização" por "acesso adequado". O termo "manejo" por "manejo do gado". Os vocábulos "assistência ao produtor" e "manutenção dos tanques" foram substituídos por "assistência técnica". "Incentivo", "incentivo do governo" e "incentivo fiscal" foram transformados para "políticas públicas". Já a palavra "qualidade do leite" foi reduzida a apenas "qualidade" (Tabela 3).

Tabela 3. Respostas dos laticínios quanto ao termo indutor

\begin{tabular}{|c|c|c|c|c|c|}
\hline Entrevistados & Palavra 1 & Palavra 2 & Palavra 3 & Palavra 4 & Palavra 5 \\
\hline Laticínio 1 & $\begin{array}{l}\text { Volume } \\
\text { produzido }\end{array}$ & Logística & Infraestrutura & $\begin{array}{c}\text { Forma de } \\
\text { pagamento }\end{array}$ & $\begin{array}{l}\text { Rebanho com } \\
\text { melhora genética }\end{array}$ \\
\hline Laticínio 2 & $\begin{array}{l}\text { Sanidade } \\
\text { animal }\end{array}$ & Higiene & $\begin{array}{l}\text { Acesso } \\
\text { adequado }\end{array}$ & Logística & Cadastro no DAP \\
\hline Laticínio 3 & $\begin{array}{l}\text { Acesso } \\
\text { adequado }\end{array}$ & Higiene & Qualidade & $\begin{array}{l}\text { Sanidade } \\
\text { animal }\end{array}$ & Preço \\
\hline Laticínio 4 & $\begin{array}{c}\text { Acesso } \\
\text { adequado }\end{array}$ & Manejo do gado & $\begin{array}{l}\text { Assistência } \\
\text { técnica }\end{array}$ & $\begin{array}{l}\text { Políticas } \\
\text { públicas }\end{array}$ & Valor agregado \\
\hline Laticínio 5 & Qualidade & Concorrência & Infraestrutura & $\begin{array}{l}\text { Políticas } \\
\text { públicas }\end{array}$ & Acesso adequado \\
\hline Laticínio 6 & Transporte & Preço & Qualidade & Armazenamento & Assistência técnica \\
\hline Laticínio 7 & Rebanho & Armazenamento & Qualidade & Preço & Volume produzido \\
\hline Laticínio 8 & $\begin{array}{l}\text { Acesso } \\
\text { adequado }\end{array}$ & $\begin{array}{l}\text { Políticas } \\
\text { públicas }\end{array}$ & $\begin{array}{l}\text { Manejo do } \\
\text { gado }\end{array}$ & Higiene & Fiscalização \\
\hline Laticínio 9 & $\begin{array}{c}\text { Acesso } \\
\text { adequado }\end{array}$ & Sanidade animal & $\begin{array}{l}\text { Tanque de } \\
\text { resfriamento }\end{array}$ & Higiene & Preço \\
\hline
\end{tabular}

Fonte: Elaboração própria. 


\section{RESULTADOS E DISCUSSÃO}

Realizada a adequação da matriz de resultados, aplicou-se a técnica de análise de frequências múltiplas, análise de similitude das palavras evocadas e análise prototípica. Dessa forma, geraramse as Tabelas 3 e 4 e as Figuras 1 a 4 com os resultados. Nas Tabelas 3 e 4, são apresentadas, por grupo, as principais palavras que se destacaram por ordem de frequência nas evocações. Nas Figuras 1 e 2, os elementos são indicados por conexão e relevância. Já nas Figuras 3 e 4, os termos são exibidos em quatro quadrantes, por nível de frequência e ordem de evocações.

\subsection{Produtores de leite}

Os nove produtores de leite responderam ao TALP, que tinha como fator indutor a seguinte pergunta: "O que faz seu leite melhor que o do concorrente? Responda em cinco palavras".

\subsubsection{Análise de frequências múltiplas}

Na análise de frequências múltiplas (Tabela 4), as primeiras palavras mais evocadas foram "higiene" e "qualidade", tendo cada uma a frequência de sete repetições e 15,56\% das evocações. Em segundo lugar, a palavra "sanidade animal" com cinco repetições e 11,11\% das evocações. Em terceiro lugar, com três repetições e 6,67\% das evocações, as palavras "manejo do gado" e "dieta apropriada". Em quarto lugar, ficaram para as palavras "ordenha mecânica", "laticínio" e "leite sem resíduo" com duas repetições e 4,44\% das evocações cada uma.

Tabela 4. Análise de frequências múltiplas

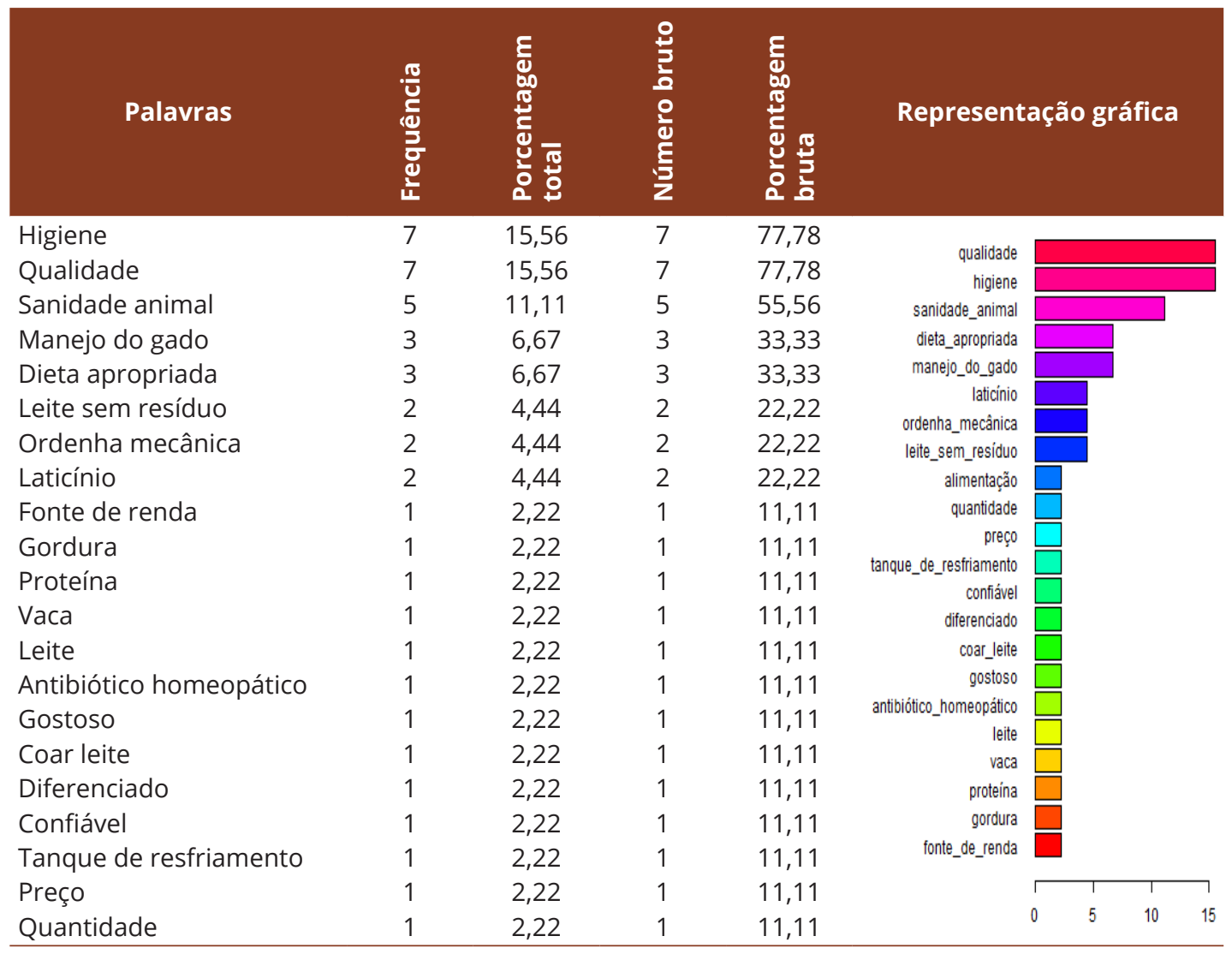

Fonte: elaboração própria. 
Verifica-se que, para o produtor de leite da região, fatores como higiene, qualidade do leite e sanidade do animal são itens muito importantes para que seu produto seja atraente ao laticínio e tenha destaque entre os demais concorrentes, pois foram os que tiveram mais evocações na pesquisa. Além disso, a análise também demonstra que o manejo e a dieta apropriada das vacas são relevantes, pois foram evocadas três vezes, como também possuem relação, pois um dos pilares do manejo do gado é a dieta apropriada, inferindo-se que sua ausência poderia causar impacto negativo na produtividade.

Pode-se destacar alguns fatores preponderantes para uma boa comercialização do leite a preços mais altos: o produtor precisa que sua vaca seja um animal saudável; que a produção de leite seja precedida de manejo adequado, com ênfase na dieta apropriada e com o uso de ordenha mecânica; que o leite produzido seja sem resíduos, necessitando, portanto, ser manipulado de forma higiênica e, dessa forma, chegue a um bom nível de qualidade, como afirma Telles et al. (2017).

\subsubsection{Análise de similitude}

De acordo com Salviati (2017), a análise de similitude possibilita identificar co-ocorrências entre as palavras e seu resultado mostra conexidade entre elas, auxiliando na identificação da estrutura da representação. Segundo esse autor, a análise mostra um grafo (árvore máxima) que representa o elo entre as palavras do corpus textuale facilita o reconhecimento dos temas de relativa importância. Conforme a árvore de co-ocorrência apresentada na Figura 2, os resultados indicam que os termos que apresentaram mais ligações foram higiene, qualidade, sanidade animal, dieta apropriada e manejo do gado. A palavra "higiene" teve conexidade com "laticínio", "ordenha mecânica" e "leite sem resíduos", demonstrando que têm consciência de que para a indústria do leite esses três critérios são relevantes na escolha do produtor que comercializará o leite.

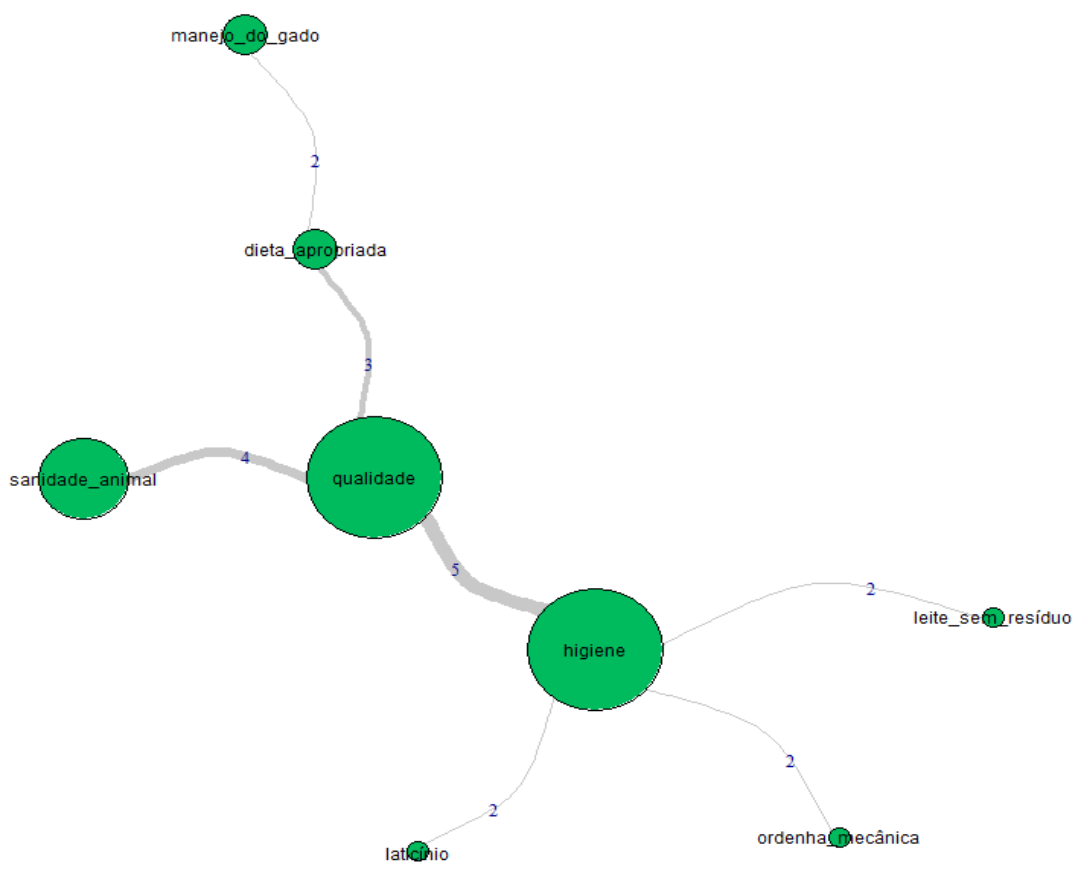

Figura 2. Análise de similitude. Fonte: elaboração própria. 
A palavra "qualidade" está diretamente ligada às palavras "sanidade animal", "dieta apropriada" e "manejo do gado". Com isso, entende-se que a dieta e o manejo do animal são fatores que influenciam na qualidade do leite e, além disso, o fato de o animal ser saudável também é um fator considerado relevante nessa qualidade, o que, segundo Busanello et al. (2017), leva a uma melhor remuneração pelo leite.

\subsubsection{Análise prototípica}

Como mostra a Tabela 5, no Núcleo Central, a palavra "qualidade" teve mais frequência que a média. Além disso, verifica-se que participa sozinha desse quadrante, ou seja, reflete o núcleo central da representação social do grupo. Nessa zona, geralmente, encontram-se elementos de alta frequência e baixa OME. Assim, exemplificou-se com a palavra "qualidade $f=7$ e OME = 2,6" o cálculo da OME, em que em $f 1$ a palavra se repetiu quatro vezes, $f 2$ não ocorreu, em $f 3$ não ocorreu, f4 a palavra ocorreu uma vez e em f5 a palavra se repetiu duas vezes (Equação 2):

$$
\frac{(4 * 1)+(0 * 2)+(0 * 3)+(1 * 4)+(2 * 5)}{7}=2,571 \text { ou } \approx 2,6
$$

Tabela 5. Análise prototípica

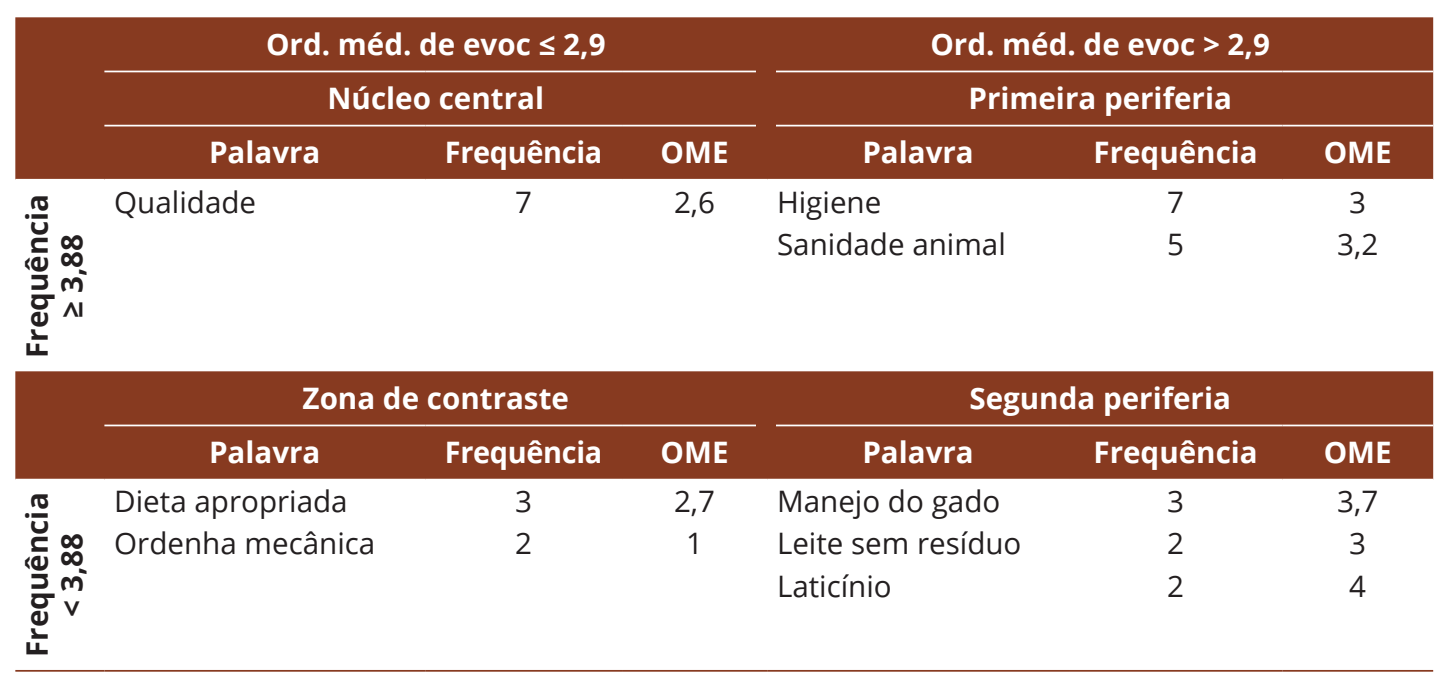

Fonte: elaboração própria.

A zona da primeira periferia, que se localiza no segundo quadrante (superior direito), inclui respostas com alta frequência e alta ordem de evocação Nessa zona, encontram-se as palavras "higiene $f=7$ e OME = 3" e "sanidade animal $f=5$ e OME = 3,2".

Entre as respostas com frequências de evocação inferiores, há a segunda periferia (inferior direito), que inclui aqueles evocados como últimas respostas. Os termos "manejo do gado $f=3$ e OME $=3,7$ ", "leite sem resíduos $f=2$ e OME = 3" e "laticínios $f=2$ e OME $=4$ " estão concentrados nesse quadrante.

As respostas com baixas frequências prontamente evocadas no discurso formam o que se chama de zona de contraste (inferior esquerdo). Segundo a Figura 2, os elementos que constam nessa zona são "dieta apropriada $f=3$ e OME =2,7" e "ordenha mecânica $f=2$ e OME = 1".

Ao analisar os resultados, percebeu-se que as palavras "qualidade", que é o núcleo central, "sanidade animal" e "higiene", que são da primeira periferia, possuem relação entre si e 
apresentam o grau de condição que o leite precisaria ter para ser atrativo ao laticínio. Pode-se inferir que o leite só poderia ser de qualidade se fosse manipulado respeitando as normas de higiene e se o animal fosse saudável, o que, segundo Meehan et al. (2016), faz parte das normas institucionais do mercado.

\subsection{Gestores institucionais de apoio à cadeia do leite, gestores de associações e cooperativas}

Os gestores de instituições de apoio à cadeia do leite (SEBRAE, SENAR) e gestores de associações e cooperativas da região responderam ao TALP com o fator indutor: "Quando se fala em cadeia do leite, quais as cinco primeiras palavras que vêm à sua mente"?

\subsubsection{Análise de frequência múltiplas}

$\mathrm{Na}$ análise de frequências múltiplas (Tabela 6), notou-se que a primeira palavra mais evocada foi "produtividade", com quatro repetições e um total de $16 \%$ de evocações. Em segundo lugar, destacou-se "preço" com três repetições e 12\% das evocações. Em terceiro lugar, com duas repetições e $8 \%$ das evocações, cada uma, as palavras "acesso adequado", "agroindústria", "qualidade", "capacitação" e "conhecimento".

Tabela 6. Análise de frequências múltiplas

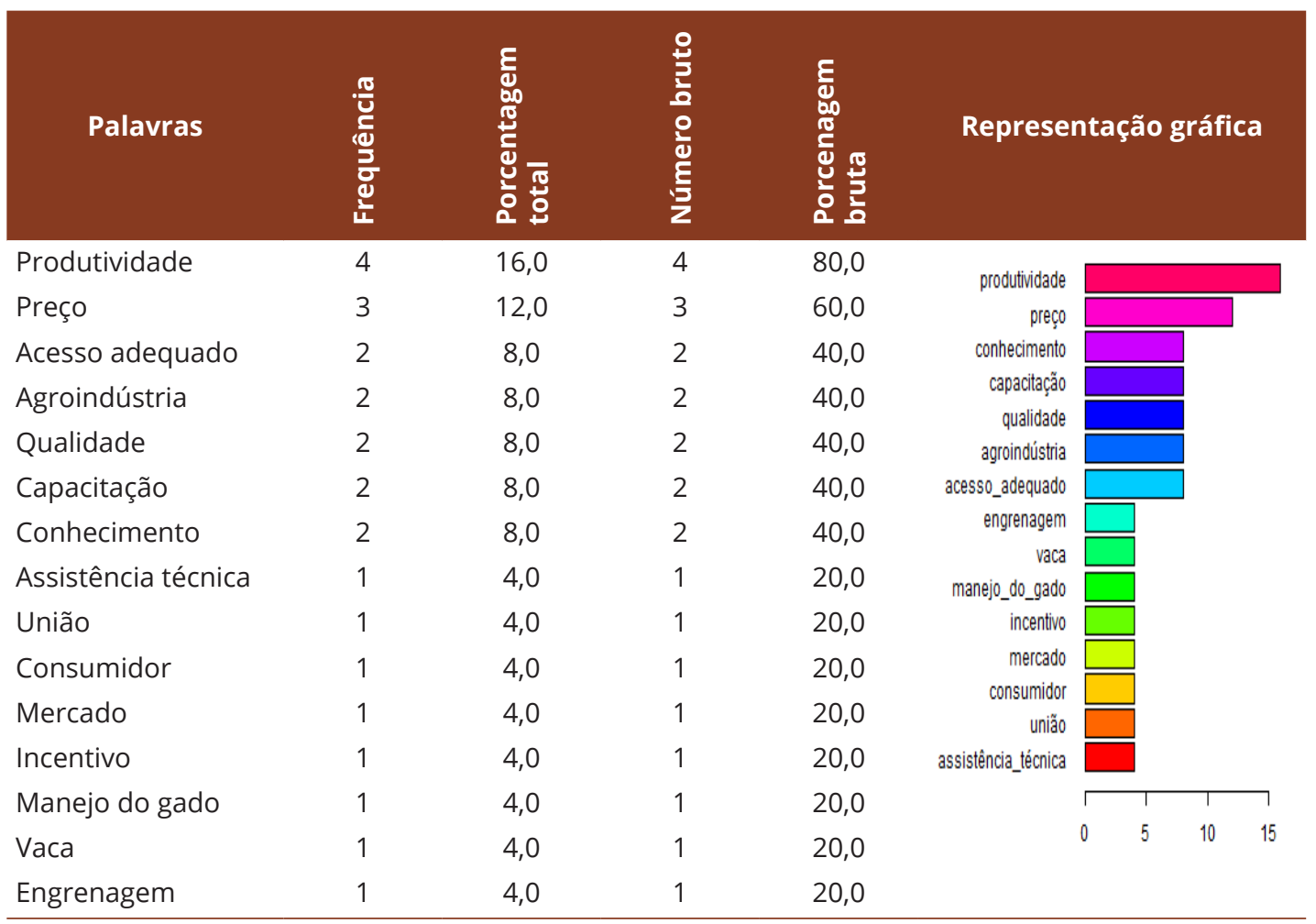

Fonte: elaboração própria.

Com base nos resultados apresentados, conclui-se que, para os gestores, associações e cooperativas da região, os itens que se evidenciam, quando se fala em cadeia do leite, são produtividade e preço. A baixa produtividade eleva o custo de produção e gera prejuízos ao produtor 
rural (Rauta et al., 2017). Outro ponto em destaque, segundo os participantes da pesquisa, é um indicativo de que é necessário mais aprendizagem por meio de capacitações e assistência técnica em vários aspectos da área leiteira, como manejo do gado, alimentação adequada, adequação do capim, análise de solo e gestão do negócio. Todos esses fatores visam ajustar a produtividade e melhorar os lucros. A maioria dos produtores não especializados evidencia na atividade uma atividade de subsistência, não levando em conta a importância da assistência técnica nem a capacitação para aumentar a produtividade e ser competitivo no mercado.

\subsubsection{Análise de similitude}

Conforme as co-ocorrências apresentadas na Figura 3, os resultados indicaram que os elementos com mais conexão foram "produtividade", "conhecimento", "preço", "qualidade" e "agroindústria". Dessas palavras, ramificam-se outras com significações expressivas, como "capacitação" e "acesso adequado". Assim como na análise das palavras dos produtores rurais, aqui o termo "qualidade" também ganha destaque e relaciona-se com "manejo do gado", demonstrando que os dois grupos associam a qualidade do leite ao processo de atividades diariamente desenvolvidas com o rebanho. A "capacitação" e a "assistência técnica" também se conectam com "manejo do gado". Nesse sentido, pode-se afirmar que capacitar os produtores e investir em assistência técnica aperfeiçoaria a forma como o gado é manuseado com consequente ganho na produtividade.

As evocações dos participantes mostram que a produtividade é resultado do conhecimento adquirido por meio de capacitação e incentivos de políticas públicas voltadas à produção de leite. Essa política também seria necessária para melhorar a infraestrutura das estradas de acesso às propriedades rurais. Vega \& Keenan (2016) destacam a importância da conectividade estrutural no campo organizacional e institucional, uma vez que as organizações se conectam umas às outras, adquirindo conhecimento e trocas relacionais que geram resultado de mercado satisfatório às necessidades de ambos os lados (Figura 3).

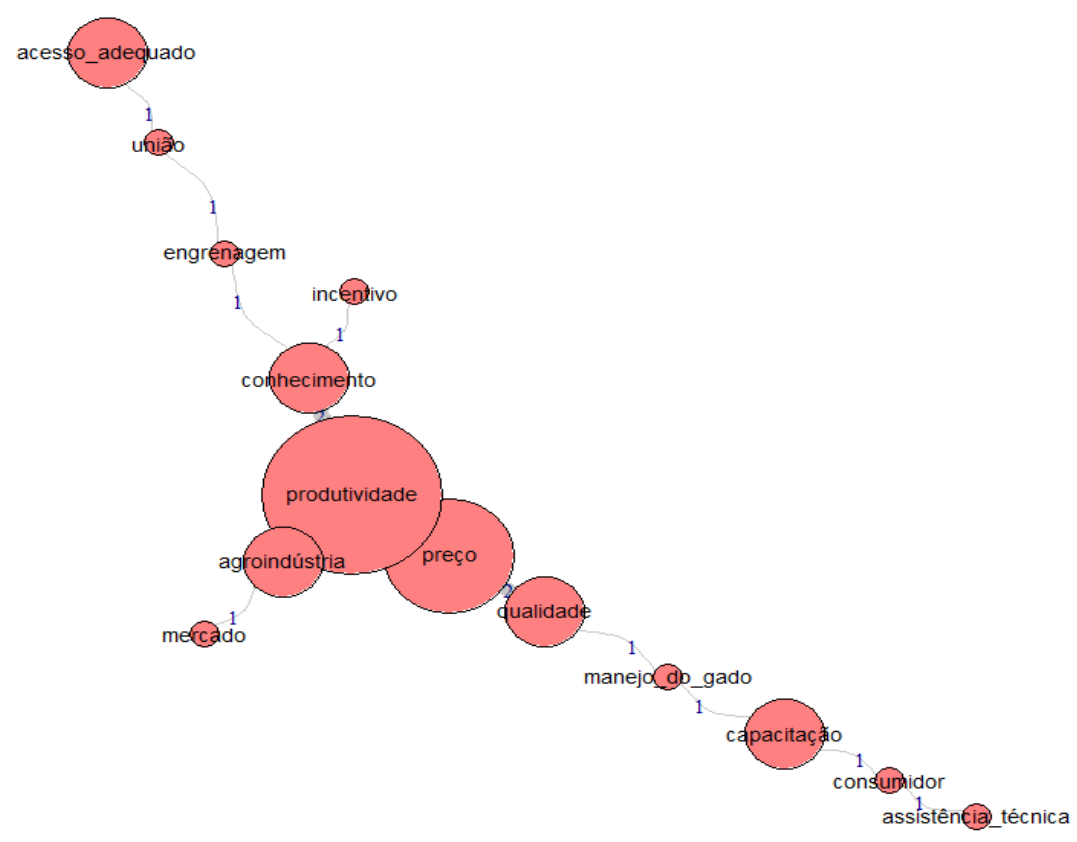

Figura 3. Análise de similitude. Fonte: elaboração própria. 
Todo o processo da cadeia do leite depende da parceria entre produtores rurais, laticínios, associações, cooperativas e governos, cada um com suas respectivas responsabilidades. Nesse contexto, a palavra "engrenagem", que está conectada com "união", exprime essa ideia de conexão entre todas as partes envolvidas e a importância de todos nesse mecanismo.

\subsubsection{Análise prototípica}

Como mostra a Tabela 7, as palavras que se destacaram no núcleo central (superior esquerdo) foram "acesso adequado $f=2$ e OME $=3$ ", "agroindústria $f=2$ e OME $=2,5$ " e "qualidade $f=2$ e $\mathrm{OME}=2,5^{\prime \prime}$. São os elementos que tiveram mais frequência no primeiro rang de evocações. Ao relacionar o termo "acesso adequado" com cadeia do leite, verifica-se que a análise prototípica demonstra confirmação sobre as dificuldades logísticas que a agroindústria da região enfrenta na coleta do leite e esse fator poderia alterar as características qualitativas do produto.

Tabela 7. Análise prototípica

\begin{tabular}{|c|c|c|c|c|c|c|}
\hline & \multicolumn{3}{|c|}{ Ord. méd. de evoc $\leq 3$} & \multicolumn{3}{|c|}{ Ord. méd. de evoc $\geq 3$} \\
\hline & \multicolumn{3}{|c|}{ Núcleo central } & \multicolumn{3}{|c|}{ Primeira periferia } \\
\hline & Palavra & Frequência & OME & Palavra & Frequência & OME \\
\hline \multirow{6}{*}{ 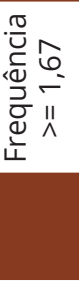 } & Acesso adequado & 2 & 3 & Produtividade & 4 & 3,5 \\
\hline & Agroindústria & 2 & 2,5 & Preço & 3 & 4 \\
\hline & Qualidade & 2 & 2,5 & Capacitação & 2 & 5 \\
\hline & & & & Conhecimento & 2 & 3,5 \\
\hline & \multicolumn{3}{|c|}{ Zona de contraste } & \multicolumn{3}{|c|}{ Segunda periferia } \\
\hline & Palavra & Frequência & OME & Palavra & Frequência & OME \\
\hline \multirow{6}{*}{ 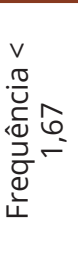 } & Assistência técnica & 1 & 2 & Consumidor & 1 & 4 \\
\hline & União & 1 & 1 & Mercado & 1 & 4 \\
\hline & Incentivo & 1 & 1 & & & \\
\hline & Manejo do gado & 1 & 1 & & & \\
\hline & Vaca & 1 & 1 & & & \\
\hline & Engrenagem & 1 & 2 & & & \\
\hline
\end{tabular}

Fonte: elaboração própria.

A primeira periferia (superior direito) apresenta as palavras com alta frequência e alta OME. São termos pensados em último caso, por isso possuem menos importância que os primeiros evocados. Nessa periferia, a palavra que mais se destacou foi "produtividade $f=4$ e OME $=$ $3,5^{\prime \prime}$, porém não teve tanta importância quanto o núcleo central, vindo a ser evocada em última ordem. O significado dessa palavra evoca que quanto maior a produção de leite dos produtores de leite, maior o interesse dos laticínios em firmarem contratos e, consequentemente, em desenvolver a região, gerando emprego, renda e atraindo novas agroindústrias que utilizam o leite como matéria-prima principal.

A segunda periferia mostra elementos que tiveram baixa frequência e alta OME, ou seja, são termos evocados poucas vezes e, por essa circunstância, esse quadrante é o mais desvalorizado da matriz. Fazem parte desse quadrante: "consumidor $f=1$ e OME $=4$ " e "mercado $f=1 \mathrm{e}$ $\mathrm{OME}=4$ ". É possível inferir que há preocupação dos participantes da pesquisa em relação aos consumidores finais e ao mercado leiteiro da região.

$\mathrm{Na}$ zona de contraste, ficam os termos de baixa frequência e baixa OME. Esse quadrante não é tão valorizado quanto deveria por apresentar palavras que possuem baixa frequência. 
Apesar disso, sua importância se dá por serem as primeiras palavras que vieram à mente dos pesquisados. Com mais evocação, a "assistência técnica $f=1$ e OME = 2" correspondem à orientação e à capacitação, ou seja, o produtor precisaria utilizar a assistência técnica como forma de melhorar a eficiência e a rentabilidade na produção. O segundo termo mais evocado foi "união $f=1$ e OME = 1" e diz respeito à necessidade de união entre produtores rurais, associações, cooperativas e governos, como meio de fortalecer o agronegócio na região. Em terceiro lugar, em destaque aparece o vocábulo "incentivo $f=1$ e $O M E=1$ ", que indica a carência de programas de incentivos pelo governo envolvendo capacitação.

\subsection{Laticínios}

Aqui constam nove laticínios que adquirem leite dos produtores das regiões sul e oeste do Maranhão. Nessa análise TALP, o estímulo indutor foi: "Quais os cinco pontos essenciais para que o laticínio adquira leite de um pequeno produtor"?

\subsubsection{Análise de frequências múltiplas}

A palavra "acesso adequado" destacou-se com mais evocações, frequência de seis repetições e total de 13,33\% das ocorrências. Os elementos "preço", "qualidade", "higiene" e "politicas públicas" encontram-se em segundo lugar, com quatro repetições e 8,89\% das evocações. Em quarto lugar, revelam-se os termos "logística", "sanidade animal", "assistência técnica", "armazenamento", "infraestrutura", "manejo do gado" e "volume produzido", com duas repetições e 4,44\% do total de evocações cada um. Os vocábulos "fiscalização", "rebanho com melhoria genética", "concorrência", "cadastro no DAP", "tanque de resfriamento", "sanidade animal", "forma de pagamento" e "rebanho" tiveram apenas uma repetição e não são apresentados na Tabela 8.

Tabela 8. Análise de frequências múltiplas

\begin{tabular}{|c|c|c|c|c|c|}
\hline Palavras & $\frac{\text { 음 }}{\frac{\text { d] }}{2}}$ & 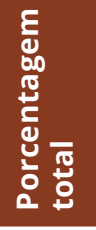 & 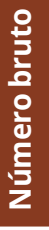 & 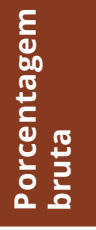 & Representação gráfica \\
\hline Acesso adequado & 6 & 13,33 & 6 & 66,67 & Acesso_adequado \\
\hline Preço & 4 & 8,89 & 4 & 44,44 & $\begin{array}{r}\text { Politicas_públicas } \\
\text { Higiene }\end{array}$ \\
\hline Qualidade & 4 & 8,89 & 4 & 44,44 & $\begin{array}{r}\text { Qualidade } \\
\text { Preço }\end{array}$ \\
\hline Higiene & 4 & 8,89 & 4 & 44,44 & $\begin{array}{l}\text { volume_produzido } \\
\text { Manejo_do_gado }\end{array}$ \\
\hline Políticas públicas & 4 & 8,89 & 4 & 44,44 & $\begin{array}{r}\text { Infraestrutura } \\
\text { Armazenamento }\end{array}$ \\
\hline Logística & 2 & 4,44 & 2 & 22,22 & $\begin{array}{l}\text { Assistência_técnica } \\
\text { sanidade_animal }\end{array}$ \\
\hline Sanidade animal & 2 & 4,44 & 2 & 22,22 & $\begin{array}{r}\text { Logística } \\
\text { Rebanho }\end{array}$ \\
\hline Assistência técnica & 2 & 4,44 & 2 & 22,22 & $\begin{array}{l}\text { Forma_de_pagamento } \\
\text { Sanidade_Animal }\end{array}$ \\
\hline Armazenamento & 2 & 4,44 & 2 & 22,22 & $\begin{array}{r}\text { Tanque_de Resfriamento } \\
\text { Cadastro_no_Dap }\end{array}$ \\
\hline Infraestrutura & 2 & 4,44 & 2 & 22,22 & $\begin{array}{c}\text { Concorrência } \\
\text { Transporte }\end{array}$ \\
\hline Manejo do gado & 2 & 4,44 & 2 & 22,22 & $\begin{array}{r}\text { rebanho_com_melhoria_genética } \\
\text { Fiscalização }\end{array}$ \\
\hline Volume produzido & 2 & 4,44 & 2 & 22,22 & $\begin{array}{llll} & 1 & 1 \\
0 & 2 & 4\end{array}$ \\
\hline
\end{tabular}

Fonte: elaboração própria.

Com base nos resultados e na percepção dos laticínios, o acesso adequado foi o principal fator para se adquirir leite de um pequeno produtor, tendo em vista ser o termo com mais 
destaque. Esse mesmo elemento foi expressivo na análise dos gestores institucionais, de associações e cooperativas, evidenciando a importância das condições das estradas e o quanto estas interferem no escoamento da produção de leite do pequeno produtor. Nesse sentido, a logística teve relevância na análise, pois, apesar de possuir conceito mais abrangente, inclui as boas condições das estradas. Uma boa logística permite que o produto seja transportado de forma rápida, adequada e eficiente, pois o leite não pode demorar a chegar à indústria pela sensibilidade das suas propriedades nutricionais.

Observou-se também que, para os laticínios, as variáveis preço, qualidade e higiene foram atributos considerados relevantes para adquirir leite de um pequeno produtor. Essas mesmas palavras também ganharam destaque nas análises dos dois grupos anteriores. Com isso, confirma-se que na visão de todos os agentes participantes dessa pesquisa essas três características são primordiais para captação, comercialização e gestão da cadeia do leite na região. Segundo a Empresa Brasileira de Pesquisa Agropecuária (2015), é possível inferir que, quanto aos critérios de compra, os laticínios avaliam as políticas públicas e a infraestrutura das regiões onde seus fornecedores atuam. Foi relatado pelos gestores que estados e municípios não oferecem infraestrutura adequada à zona rural das regiões em análise, como água e energia elétrica nas propriedades rurais, além de não praticarem incentivos fiscais suficientes para atrair indústrias para a região.

Sanidade animal, assistência técnica e manejo do gado revelaram-se importantes na pesquisa e apresentam-se como critérios de compra para a indústria do leite. Essas palavras também tiveram evocações significativas na análise dos produtores rurais, indicando que os dois grupos julgam essenciais as orientações técnicas e boas práticas de manejo, para ter um animal saudável e leite com boa aceitabilidade pelos laticínios. Destacam-se, ainda, as palavras armazenamento e volume produzido. Infere-se que o laticínio tem como requisito padrão a forma como o produtor armazena o produto e se está de acordo com os protocolos técnicos de temperatura e conservação, como aponta Silveira (2018). Outro requisito é o volume de leite produzido a fim de compensar custos com transportes e logística.

\subsubsection{Análise de similitude}

Diante dos resultados apresentados na Figura 4, revela-se a centralidade de três blocos distintos: "acesso adequado", "qualidade" e "preço", os quais mantêm conexidade entre si e com outros elementos. Tais conexões indicam que estradas ruins podem prejudicar a qualidade do leite em razão do tempo de trajeto e, consequentemente, o preço de venda cairia.

O problema com o acesso também incentiva a contratação de atravessadores pelos produtores de leite, contudo seu lucro diminui, pois parte do valor do produto fica com o atravessador como forma de pagamento pelo frete. Observa-se que "acesso adequado" se conecta diretamente com "políticas públicas" e "higiene", pressupondo a necessidade de programas governamentais que invistam em melhorias nas estradas de acesso às propriedades rurais, e reforça a ideia de que o acesso adequado melhora o tempo de entrega do leite ao tanque de resfriamento, evitando proliferação de bactérias.

Os elementos "preço", "armazenamento", "assistência técnica" e "qualidade" possuem conexão direta. Com isso, presume-se que, respeitadas as normas técnicas de conservação e armazenamento do leite, sua qualidade será preservada e, como resultado, seu preço será valorizado. Por meio das conexões entre as palavras "volume produzido", "infraestrutura" e "logística", pode-se considerar que o custo de transporte é alto também pela falta de infraestrutura nas regiões. Portanto, se o volume de leite produzido for pequeno, não compensará a viagem. 


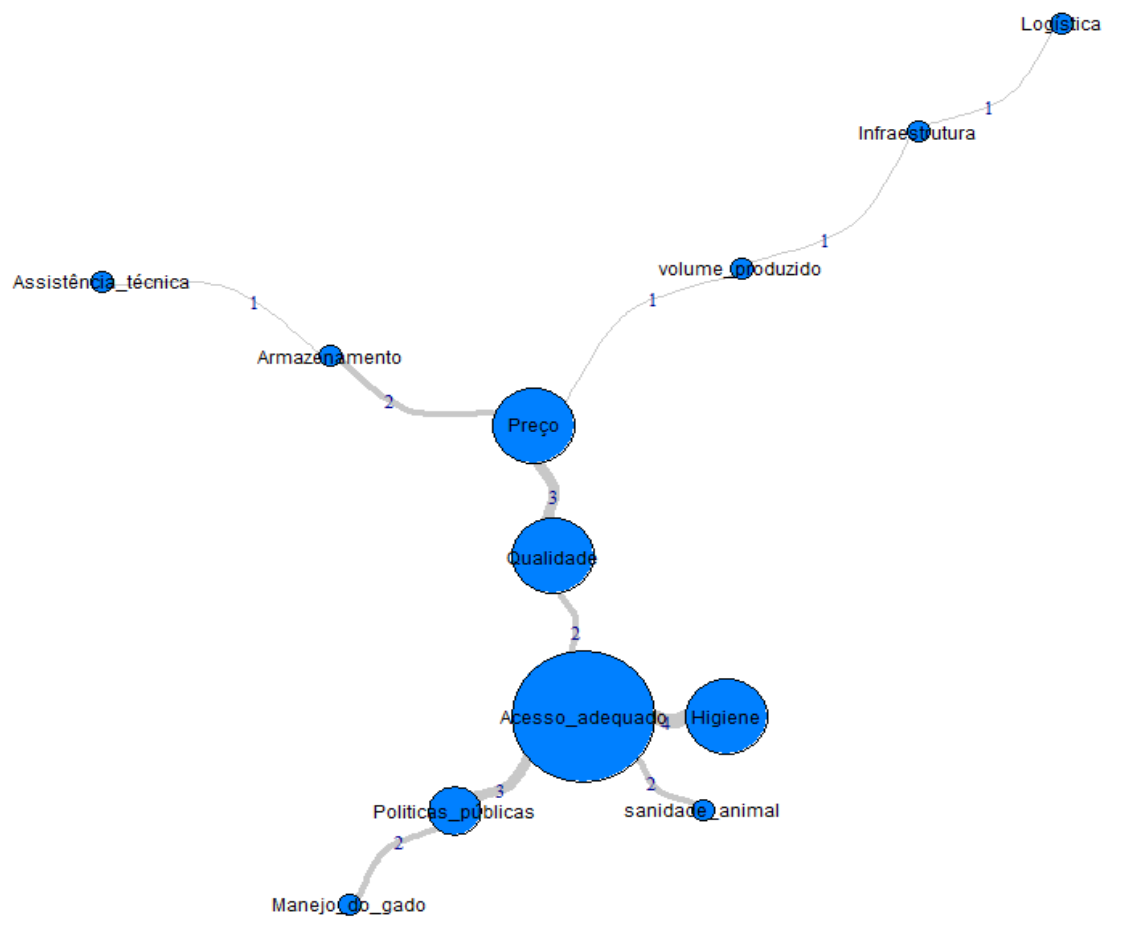

Figura 4. Análise de similitude. Fonte: elaboração própria.

\subsubsection{Análise prototípica}

Como mostra a Tabela 9, as palavras que se destacaram no núcleo central (superior esquerdo) foram "acesso adequado $f=6$ e OME $=2$ " e "qualidade $f=4$ e OME $=2,5$ ". Ao relacionar a palavra "acesso adequado" e "qualidade" ao termo indutor, percebe-se a importância dada aos laticínios para as boas condições das estradas que dão acesso às propriedades rurais e o quanto isso acaba influenciando na qualidade do leite em razão das longas distâncias percorridas até um tanque de resfriamento mais próximo.

Tabela 9. Análise prototípica

\begin{tabular}{|c|c|c|c|c|c|c|}
\hline & \multicolumn{3}{|c|}{ Ord. méd. de evoc $\leq 2,92$} & \multicolumn{3}{|c|}{ Ord. méd. de evoc > 2,92 } \\
\hline & \multicolumn{3}{|c|}{ Núcleo central } & \multicolumn{3}{|c|}{ Primeira periferia } \\
\hline & Palavra & Frequência & OME & Palavra & Frequência & OME \\
\hline \multirow{5}{*}{ 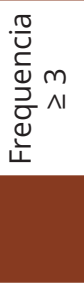 } & Acesso adequado & 6 & 2 & Preço & 4 & 4 \\
\hline & Qualidade & 4 & 2,5 & Higiene & 4 & 3 \\
\hline & & & & Políticas públicas & 4 & 3,8 \\
\hline & \multicolumn{3}{|c|}{ Zona de contraste } & \multicolumn{3}{|c|}{ Segunda periferia } \\
\hline & Palavra & Frequência & OME & Palavra & Frequência & OME \\
\hline \multirow{5}{*}{ 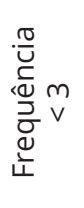 } & Sanidade animal & 2 & 1,5 & Logística & 2 & 3 \\
\hline & Manejo & 2 & 2,5 & Assistência técnica & 2 & 4 \\
\hline & & & & Armazenamento & 2 & 3 \\
\hline & & & & Infraestrutura & 2 & 3 \\
\hline & & & & Volume produzido & 2 & 3 \\
\hline
\end{tabular}

Fonte: elaboração própria. 
Destacam-se na primeira periferia (superior direito) as palavras "preço $f=4$ e OME $=4$ ", "higiene $f=4$ e OME = 3" e "políticas públicas". O termo "preço" se relaciona com o valor ofertado pelos produtores aos laticínios, fator determinante para decisão de compra.

Na segunda periferia (inferior direito), encontram-se os elementos "logística $f=2$ e OME = 3", "assistência técnica $f=2$ e OME $=4$ " e "armazenamento $f=2$ e OME = 3". Constam nesse quadrante as palavras que foram evocadas poucas vezes pelos participantes da pesquisa. Pode-se inferir que há certo receio dos laticínios com o processo de captação, transporte e entrega do leite e com a forma de armazenamento feita pelos produtores.

Na zona de contraste (inferior esquerdo), encontram-se as primeiras palavras evocadas pelos entrevistados quando estimulados pelo termo indutor. Estão presentes nessa zona as palavras "sanidade animal $f=2$ e OME =1,5" e "manejo do gado $f=2$ e OME =2,5".

\section{CONSIDERAÇÕES FINAIS}

Os resultados apresentados permitiram identificar a forma como os agentes do SAG do leite percebem e praticam a produção e a comercialização, bem como as relações entre eles, na busca por estratégias competitivas regionais. O estudo mostrou-se oportuno, sustentado pelo contexto da prática e vivência dos agentes que compõem essa cadeia, considerando os ambientes organizacional e institucional. Foram levantadas, por meio da livre evocação de palavras, informações sobre os aspectos de produção e comercialização do leite proveniente de pequenos produtores, bem como desafios, opiniões e práticas do mercado leiteiro nas regiões analisadas. Esse modelo oferece indicações sobre os conteúdos concernentes ao SAG do leite, que podem ser mais bem desenvolvidos para melhorar a produtividade, a renda, os custos, a produção e a qualidade do leite proveniente de pequenos produtores.

A pesquisa revelou como fatores impeditivos e desafios para o melhor desenvolvimento da produção e comercialização do leite a precária infraestrutura e logística para captação e transporte do leite in natura, bem como o difícil acesso às propriedades rurais, caracterizandose como um importante desafio para o crescimento do mercado leiteiro regional. Ao comparar os resultados, percebeu-se que todos os agentes citaram em suas falas, considerando critérios mercadologicamente importantes a qualidade do leite, a higiene, a sanidade animal, o uso de ordenha mecânica e a assistência técnica aos pequenos produtores. Isso demonstra a uniformidade das percepções sobre as condições do SAG do leite e a integração nos relacionamentos entre produtores, gestores dos laticínios e agentes de assistência técnica.

Na análise do SAG da região, também foi possível identificar alguns aspectos organizacionais a serem mais bem estruturados, como a falta de coordenação da cadeia, exigindo melhor organização dos pequenos produtores em associações ou cooperativas. Essa iniciativa não se daria apenas como um entreposto, mas como um agente agregador importante para que a assistência técnica e o poder de negociação no mercado sejam mais eficientes.

Mesmo com a identificação de tais problemas, foi possível levantar alguns aspectos oportunos ao SAG na região, como o início da organização dos produtores para a utilização de tanques de resfriamento e a sucessão de pais para filhos em algumas propriedades, tendo os filhos segundo grau completo e outros cursando graduação. Essa prospecção tende a atenuar os impactos negativos da utilização de tecnologia encontrados nas regiões analisadas e vista como uma conjuntura de melhor aproveitamento das oportunidades advindas dos ambientes institucional e organizacional. Percebeu-se que todos os agentes pesquisados estão cientes de que o país tende a investir no aumento da produção e da produtividade do leite, porém a 
legislação sanitária tenderá a ser mais exigente, ponto esse que traz a necessidade de adequação aos agentes do SAG do leite para se tornarem mais competitivos.

Nesse aspecto, Gonçalves et al. (2017) evidenciaram que o perfil tradicional de alguns produtores resultou em resistência a mudanças, levando a um desalinhamento de produtividade no SAG do leite. Por outro lado, os produtores que modernizaram suas propriedades para atender à demanda conseguiram se adaptar, coordenando melhor a relação produção e custos e promovendo desenvolvimento no SAG. No Brasil, a cadeia do leite é pulverizada, coexistindo produtores altamente especializados com capacidade de produção em escala e outros produtores não especializados, cuja produtividade é baixa e que apresentam mais dificuldade para produzir leite com a qualidade exigida pelos laticínios. Os sistemas de incentivo à padronização e melhoria da qualidade do leite são uma necessidade real do SAG aqui apresentado, considerados fundamentais para garantir a inserção de pequenos produtores de forma competitiva no mercado. Como estudos futuros, sugere-se uma análise da cadeia de produção leiteira das regiões sul e oeste do Maranhão, envolvendo todos os agentes que a compõem, levantando também os custos de produção, bem como os comparando às principais cadeias produtivas de leite das regiões mais desenvolvidas do país.

\section{Agradecimentos}

Agradecemos à Fundação de Amparo à Pesquisa e ao Desenvolvimento Científico e Tecnológico do Maranhão (FAPEMA) o apoio financeiro fornecido para a realização desta pesquisa.

\section{Referências}

Acosta, D. C., Souza, J. P., \& Bankuti, S. M. S. (2018). Tecnificação de produtores e estruturas de governança no sistema agroindustrial de leite. Desenvolvimento em Questão, 16(45), 292-315.

Azevedo, P. F., \& Politi, R. B. (2008). Concorrêncioa e estratégias de precificação no sistema agroindustrial do leite. Revista de Economia e Sociologia Rural, 46(3), 767-802.

Balde Branco. (2016). Alguns números do leite. Recuperado em junho de 2020, de https:// baldebranco.com.br/alguns-numeros-do-leite/

Börjeson, L. (2015). Interorganizational situations: an explorative typology. European Management Journal, 33(3), 191-200.

Botaro, B. G., Gameiro, A. H., \& Santos, M. V. (2013). Quality based payment program and milk quality in dairy cooperatives of Southern Brazil: an econometric analysis. Scientia Agrícola, 70(1), 21-26.

Brasil. Ministério da Agricultura Pecuária e Abastecimento. (2012). Resolução n 4174, de 28 de dezembro de 2012. Recuperado em janeiro de 2021, de http://sistemasweb.agricultura. gov.br/sislegis/action/detalhaAto.do?method=visualizarAtoPortalMapa\&chave $=1797518661$

Brasil. Ministério da Mulher, da Família e dos Direitos Humanos. (2020). Manual do jovem empreendedor rural. Recuperado em janeiro de 2021, de https://www.gov.br/mdh/pt-br/ navegue-por-temas/juventude-1/manual-do-jovem-empreendedor-rural.pdf

Busanello, M., Freitas, L. N., Winckler, J. P. P., Farias, H. P., Dias, C. T., Cassoli, L. D., \& Machado, P. F. (2017). Month-wise variation and prediction of bulk tank somatic cell count in Brazilian dairy herds and its impact on payment based on milk quality. Irish Veterinary Journal, 70(1), 26. 
Campos, P. P. L. E., Rangel, A. H. D. N., Borba, L. H. F., Urbano, S. A., Novaes, L. P., Galvão Júnior, J. G. B., Sales, D. C., \& de Aguiar, E. M. (2016). Quality indicators of tank milk in different production systems of tropical regions. Semina: Ciências Agrárias, (37), 2807-2818.

Correia, J. C., \& Joia, L. A. (2014). A representação social das competências essenciais aos CIOs sob a perspectiva dos profissionais de TI. In EnANPAD (pp. 1-16).

Coutinho, M. P. L., Nóbrega, S. M., \& Catão, M. F. F. M. (2003). Contribuições teórico metodológicas acerca do uso dos instrumentos projetivos no campo das Representações Sociais. Editora Universitária.

Donato, S. P., Ens, R. T., Favoreto, E. D. A., \& Pullin, E. M. M. P. (2017). Da análise de similitude ao grupo focal: estratégias para estudos na abordagem estrutural das representações sociais. Revista Educação e Cultura Contemporânea, 14(37), 367-394.

Durr, J. W. (2012). Como produzir leite de qualidade (4. ed.). Brasília: SENAR. Recuperado em janeiro de 2021, de http://www.senar.org.br/

Empresa Brasileira de Pesquisa Agropecuária - Embrapa. (2015). Panorama do Leite, 7(81), 7-8.

Empresa Brasileira de Pesquisa Agropecuária - Embrapa. (2019). Sua excelência, o consumidor: novos produtos e novas estratégias da cadeia do leite para ganhar competitividade $e$ conquistar os clientes finais (Anuário Leite, No. 104).

Empresa Brasileira de Pesquisa Agropecuária - Embrapa. (2020). Pecuária de leite espera crescer 2\% em 2020. Recuperado em julho de 2020, de https://www.embrapa.br/busca-de-noticias/-/ noticia/49358451/pecuaria-de-leite-espera-crescer-cerca-de-2-em-2020\#: :text=Este\%20 ano\%2C\%20analistas\%20esperam\%20crescimento,2\%2C5\%25\%20em\%202019

Golban, A., \& Golban, R. (2017). Evolution of milk production in Republic of Moldova and the role of quality management in increasing the competitiveness of milk processing companies. Management, Economic Engineering and Rural Development, 17(2).

Gonçalves, J. L., Tomazi, T., \& Santos, M. V. (2017). Rotina de ordenha eficiente para produção de leite de alta qualidade. Revista Acadêmica: Ciência Animal, 15, 9.

Instituto Brasileiro de Geografia e Estatística - IBGE. (2018a). Produção da pecuária municipal 2018 (pp. 1-8). Recuperado em junho de 2020, de https://www.ibge.gov.br/estatisticas/ economicas/agricultura-e-pecuaria/9107-producao-da-pecuaria-municipal.html

Instituto Brasileiro de Geografia e Estatística - IBGE. (2018b). Produção da pecuária municipal 2018. Recuperado em junho de 2020, de https://biblioteca.ibge.gov.br/visualizacao/ periodicos/84/ppm_2018_v46_br_informativo.pdf

Krell, K., Matook, S., \& Rohde, F. (2016). The impact of legitimacy-based motives on IS adoption success: an institutional theory perspective. Information \& Management, 53(6), 683-697.

Meehan, J., Ludbrook, M. N., \& Mason, C. J. (2016). Collaborative public procurement: Institutional explanations of legitimised resistance. Journal of Purchasing and Supply Management, 22(3), 160-170.

Oliveira, E. B. (2016). Perspectivas do leite no Maranhão. Serviço Nacional de Aprendizagem Rural (SENAR). Recuperado em junho de 2020, de http://senar-ma.org.br/perspectivas-doleite-no-maranhao/

Palencia, N. P. (2016). Complexo Agroindustrial do Leite no Brasil : indicadores socioeconômicos, adoção de tecnologias e transformações nas últimas décadas. Revista de Economia Do Centro-Oeste, 2, 55-72. 
Rauta, J., Paetzold, L. J., \& Winck, C. A. (2017). Rastreabilidade na cadeia produtiva do leite como vantagem competitiva. Revista em Agronegócio e Meio Ambiente, 10(2), 459.

Salviati, M. E. (2017). Manual do aplicativo IRaMuTeQ. Iramutec. Recuperado em junho de 2020, de http://www.iramuteq.org/documentation/html

Santos, J. V. O., Araújo, L. F., Castro, J. L. D. C., \& Faro, A. (2019). Análise prototípicea das representações sociais sobre as infecções sexualmente transmissíveis entre adolescentes. Psicogente, 22(41), 1-18.

Scalco, P. R., \& Braga, M. J. (2014). Measuring the degree of oligopsony power in the Brazilian raw milk market. The International Food and Agribusiness Management Review, 17(2), 1-20.

Silva Filho, J. V., \& Figueira, S. R. F. (2019). Mensuração do impacto de variáveis econômica sobre captação de leite no estado de Minas Gerais entre 1999 e 2016: uma análise utilizando modelo de cointegração. Brazilian Journal of Development, 5(7), 10284-10300.

Silveira, R. C. (2018). O incentivo dos programas de pagamento baseado na qualidade do leite à adoção de boas práticas agropecuárias nas propriedades leiteiras: um estudo multicasos na região do Médio Paraíba Fluminense/RJ(Dissertação de mestrado). Universidade Federal Fluminense, Volta Redonda.

Sorio, A. (2018). Cadeia Agroindustrial do Leite no Brasil: diagnóstico dos fatores limitantes à competitividade (162 p.). Ministério da Indústria, Comércio Exterior e Serviços (MIDCS). Recuperado em maio de 2020, de http://www.unesco.org/new/fileadmin/MULTIMEDIA/ FIELD/Brasilia/pdf/brz_Sc_cadeia_produtiva_leite_MICS_por_2018.pdf

Tavares, D. W. S., Brito, R. C., Córdula, A. C. C., Silva, J. T., \& Neve, D. A. B. (2014). Protocolo verbal e teste de associação livre de palavras: perspectivas de instrumentos de pesquisa introspectiva e projetiva na ciência da informação. PontodeAcesso, 8, 64-79.

Telles, T. S., Bacchi, M. D., \& Shimizu, J. (2017). Spatial distribution of microregions specialized in milk production. Semina: Ciências Agrárias, 38(1), 443.

Vega, D. E. C., \& Keenan, R. (2016). Situating community forestry enterprises within New Institutional Economic Theory: what are the implications for their organization? Journal of Forest Economics, 25, 1-13.

Wachelke, J., Wolter, R., \& Matos, F. R. (2016). Efeito do tamanho da amostra na análise de evocações para representações sociais. Liberabit, 22(2), 153-160.

Zylbersztajn, D. (1995). Estruturas de governança e coordenação do agribusiness: uma aplicação da nova economia das instituições (Tese de livre docência). Faculdade de Economia, Administração e Contabilidade, Universidade de São Paulo, São Paulo. 